\title{
Sutton-Chen Potansiyel Fonksiyonu ile Cu Elementinin Örgü Kararlılığının İncelenmesi
}

\section{Investigation of Lattice Stability of Cu Element with Sutton- Chen Potential Function}

\author{
Sefa Kazanç ${ }^{1 *}$ \\ ${ }^{1 *}$ Fırat Üniversitesi, Eğitim Fakültesi, Matematik ve Fen Bilimleri Eğitimi Bölümü, 23119, Elazığ, TÜRKiYE \\ Sefa Kazanç / Corresponding Author*: skazanc@firat.edu.tr \\ Geliş Tarihi / Received: 12.07.2018 \\ DOI:10.21205/deufmd. 2019216115 \\ Kabul Tarihi / Accepted: 11.09.2018 \\ Araştırma Makalesi/Research Article
}

Atıf șekli/ How to cite: KAZANÇ, S. (2019). Sutton-Chen Potansiyel Fonksiyonu ile Cu Elementinin Örgü Kararlllı̆ııın İncelenmesi. DEUFMD, 21(61), 149-154.

$\ddot{0} \mathbf{z}$

Bu çalışmada $4000 \mathrm{Cu}$ atomu basit kübik, cisim merkezli kübik, yüzey merkezli kübik ve elmas yapının örgü noktalarına yerleștirilerek Sutton-Chen potansiyel fonksiyonunun bu atomik sistem için ürettiği kararlı örgü yapısı belirlendi. Kullanılan potansiyel fonksiyonu ifadesinde gömme enerjisinin ve yük yoğunluğunun hacimle, ikili etkileşme teriminin atomlararası mesafe ve gömme enerjisinin yük yoğunluğu ile değişimi hesaplandı. Ayrıca model sisteme Bain zorlanması ve kesme zoru uygulanarak kohesif enerjideki değişimler belirlendi. Gömülmüş atom metodunun Sutton-Chen türü potansiyel fonksiyonunun bu atomik sistemin yapısal özelliklerinin belirlenmesi için uygun değerler üretebildiği görüldü.

Anahtar Kelimeler: Sutton-Chen potansiyel fonksiyonu, katı-katı faz dönüşümleri, Bain zorlanması, kesme zoru

\section{Abstract}

In this work, $4000 \mathrm{Cu}$ atoms were placed in the lattice points of simple cubic, body-centered, cubic, surface-centered cubic and diamond structures and the stable lattice structure of the Sutton-Chen potential function for this atomic system was determined. In the used potential function expression, the variation of the embedding energy and charge density with the volume, the variation with the interatomic distance of the binary interaction term and the charge density of the embedding energy were calculated. In addition, with applying bain and shear stress on the model system were determined changes in cohesive energy. It is seen that the Sutton-Chen type potential of embedded atom method can produce suitable values to determine the structural properties of this atomic system.

Keywords: Sutton-Chen potential functions, solid-solid phase transformations, Bain distorsion, shear stress 


\section{Giriş}

Katı fazda bir kristal yapıdan daha düșük enerjili başka bir kristal yapıya geçiş katı-katı faz dönüşümleri olarak bilinmektedir. $\mathrm{Bu}$ dönüşümler esnasında malzemenin mikro yapısındaki değișiklikler makro yapıda da önemli etkilerin ortaya çlkmasına neden olduğundan bu dönüşümlerin hangi şartlar altında ve hangi mekanizmalarla meydana geldiğinin bilinmesi son derece önemlidir [1, 2] Malzemelerin makro seviyede gösterdikleri davranışlar onların atomik seviyedeki yapılarına son derece bağlıdır. Dönüșümlerin hangi șartlara bağlı olduğunun belirlenmesi, bu malzemelerin sanayi ve teknolojide etkili bir șekilde kullanılması açısından oldukça önemlidir.

Katı-katı faz geçişleriyle ilgili deneysel olarak yapılan birçok çalıșma olmasına karșılık bilgisayar teknolojisi ve hızının gelişmesi bu geçişlerin teorik olarak çalışılmasına imkan sağlamaktadır. Özelliklere faz dönüşüm mekanizmaları ve bu dönüșümlere etki eden faktörlerin anlaşılması üzerine teorik çalışılmaklar yapılmaktadır [3-6]. Element veya alașım sistemlerinin modellenmesinde en önemli faktör atomlar arasındaki etkileșmelerin belirlenmesinde kullanılan potansiyel enerji fonksiyonudur (PEF). Farklı sistemlerin modellenmesi için çok sayıda potansiyel fonksiyonu türetilmiștir $[7,8]$. İncelenecek sistemin termodinamik ve fiziksel özelliklerini dinamik olarak hesaplamadan önce kullanılan potansiyel fonksiyonunun geçerliliği belirlenmelidir. Bunun için sistemin kararlı örgü yapısının, uygulanan bain ve kesme zorları altında farklı bir kristal yapıya dönüşme eğilimine sahip olup olmadığının tespit edilmesi gerekmektedir. İncelenen sistemin hangi örgü yapısında kararlı duruma sahip olduğunu belirlemek için o sistemin hacim değișimine karşı kohesif enerjisi belirlenir. Minimum enerji değeri üreten yapı, sistem için ideal yapıya karşılık gelmektedir. Ayrıca kullanılan PEF in bir faz dönüşümünü gerçekleştirmesi için farklı yapıya sahip yarı kararlı bir enerji değeri üretmesi gerekmektedir. Bu yarı kararlı enerji seviyesi sistemin sadece hacme göre değişiminden değil farklı yönlerde uygulanan zorlarla tespit edilmektedir. Bain ve kesme zorları bu yarı kararlı örgü yapısının belirlenmesi için kullanılır [9-10].

Anharmonik etkilerin baskın olduğu katı-katı faz dönüşümlerinin modellenebilmesi için kullanılan potansiyel enerji fonksiyonlarından biri çok cisim etkileșmelerini içeren Gömülmüș
Atom Metodudur [11]. Voter-Chen [12], FinnisSinclair [13], sıkı-bağ metodu [14] ve SuttonChen [15] gömülmüş atom metodunun farklı türdeki potansiyel enerji fonksiyonlarıdır. $\mathrm{Bu}$ fonksiyonların farklı olması ikili etkileşme enerji, yük yoğunlukları ve gömme enerjisi terimlerinin farklı araştırmacılar tarafından farklı şekilde ifade edilmesinden kaynaklanmaktadır. Sutton-Chen potansiyel fonksiyonu, matematiksel olarak sade bir yapıya sahip olması ve metalik sistemleri bașarıyla modelleyebilmesi nedeniyle oldukça yaygın olarak kullanılmaktadır [16-18].

Bain distorsiyonu veya saf örgü deformasyonu ilk defa Bain tarafından ortaya atılan iki fcc yapıdan bir bcc yapının elde edildiği örgü kurgusudur. Bu kurgu fcc örgüsünün [001] ekseni boyunca $\% 20$ kısalmayı, [110] ve [110] eksenleri boyunca \%12 genişlemeyi öngörür [19-20].

$\mathrm{Bu}$ çalışmada $\mathrm{Cu}$ elementi için Sutton-Chen potansiyel fonksiyonundaki gömme enerjisinin ve yük yoğunluğunun hacimle, ikili etkileşme enerjisinin atomlar arası uzaklıkla ve gömme enerjisinin yük yoğunluğu ile değişimi belirlendi. 4000 atomdan meydana gelen $\mathrm{Cu}$ model sisteminin kararlı örgü yapısını belirlemek için $\mathrm{Cu}$ atomları basit kübik (sc), cisim merkezli kübik (bcc), yüzey merkezli kübik (fcc) ve elmas yapının örgü noktalarına yerleștirildi. Model sistemin hacim değişimine karşı birim atom başına bağlanma enerjisi (kohesif enerji) belirlendi. Ayrıca Bain zorlanması ve kesme zoru uygulanarak örgünün kararlı ve yarı kararlı yapıları tespit edilmeye çalışıldı.

\section{Materyal ve Metot}

\subsection{Gömülmüș atom metodu}

Denklem (1), Gömülmüş Atom Metodunda $N$ atomdan meydana gelen bir sistemin toplam enerjisini vermektedir.

$$
E_{\text {top }}=\sum_{i}^{N} F_{i}\left(\rho_{i}\right)+\frac{1}{2} \sum_{i \neq j} \Phi\left(r_{i j}\right)
$$

Bu ifade de $F_{i}\left(\rho_{i}\right), \rho_{i}$ yük yoğunluğuna sahip bir noktaya $i$ atomunu gömmek için gerekli olan enerjiyi, $\Phi\left(r_{i j}\right)$ iki atom arasındaki ikili etkileşme enerjisine karşılık gelmektedir. Herhangi bir noktada diğer atomların oluşturduğu yük yoğunluğu;

$$
\rho_{i}=\sum_{\substack{j=1 \\ j \neq i}} \rho_{j}^{a}\left(r_{i j}\right)
$$

fonksiyonu ile verilmektedir. 
DEU FMD 21(61), 149-154, 2019

SC potansiyel fonksiyonunda ikili etkileşme enerjisi, yük yoğunluğu ve gömme enerjisi sırasıyla;

$$
\begin{aligned}
& \Phi\left(r_{i j}\right)=\left(\frac{a}{r_{i j}}\right)^{n} \\
& \rho_{i}\left(r_{i j}\right)=\sum_{j \neq i}^{N}\left(\frac{a}{r_{i j}}\right)^{m} \\
& F_{i}\left(\rho_{i}\right)=-c \varepsilon \sqrt{\rho_{i}}
\end{aligned}
$$

ifadeleriyle belirlenmektedir [15, 21]. Çalıșmada kullanılan örgü statik durumda olduğundan ortam sıcaklığı O K ve basınç O GPa değeri olarak kabul edilir. Hesaplamanın başlangıçında atomlar örgü noktalarında hareketsizdirler ve tüm hesaplama boyunca herhangi bir hıza sahip değillerdir. Cu elementi için çalışmada kullanılan SC potansiyel parametreleri $\varepsilon=1,2382 \times 10^{-2} \mathrm{eV}$, $c=39,432, a=3,61 \AA$, $n=9$ ve $m=6$ değerindedir [22].

\subsection{Bain zorlanması ve kesme zoru}

Bain zorlanması olarak adlandırılan ve iki bitişik fcc örgüden bir bcc örgü oluşturma kurgusu Şekil 1 de gösterilmiștir. Bitişik iki fcc örgünün yüzey merkezlerinden bir bct örgü tanımlanmaktadır. Bu kurgu fcc örgünün z' ekseninde $\% 20$ lik bir kısalma ve $x^{\prime}$ ve $y^{\prime}$ eksenleri boyunca \%12 lik bir genișlemeyi öngörür. $a=b=c$ ise $b c c$ ve $a=b$ ve $c=\sqrt{2}$ ise fcc hücreler tanımlanır. Buna göre $c / a=1$ ise yapı bcc ve $c / a=1,414$ ise yapı fcc olarak kabul edilir. Dönüșüm mekanizmasıyla ilgili detaylı bilgi literatürden bulunabilir [19, 20].

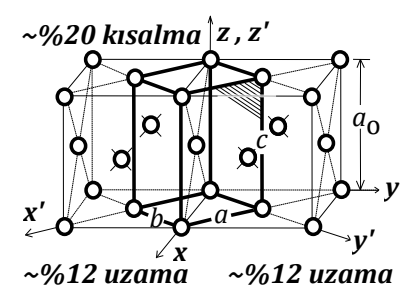

(a)

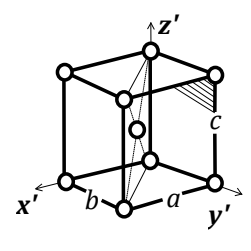

(b)
Şekil 1. Bain zorlanması. (a) bitişik iki fcc birim hücresi ve sadece koordinat seçimiyle gösterilen bct hücre (kalın çizgi), (b) bcc birim hücresi. a0, fcc örgünün örgü parametresi [19].

Kesme zoru Şekil 2 de görüldügü gibi yüzeye paralel uygulanan bir $S$ kesme vektörü atomik düzlemlerin birbiri üzerinde kaymalarına sebep olmaktadır. Sistemin hacmi sabit tutularak enerjide meydana gelen değişim önlenmeye çalışmış ve dönüșüm enerjisinin sadece kristal geometrisine bağlı kalması sağlanmıștır. Yapılan çalıșmada hesaplama hücresinin hacmi sabit tutularak $S$ kesme vektörüne bağlı olarak sistemin enerjisi değişimi hesaplanmıştır.

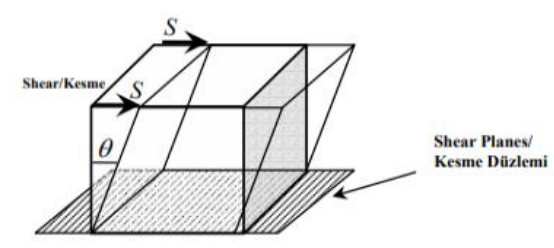

Șekil 2. Kesme zoru

\section{Bulgular}

Cu elementinin kararlı örgü yapısını tespit etmek için $\mathrm{Cu}$ atomları basit kübik (sc) (4096 atom), hacim merkezli kübik (bcc) (4394 atom), yüzey merkezli kübik (fcc) (4000 atom) ve elmas (4096 atom) yapının örgü noktalarına yerleștirildi ve her bir yapı için kohesif enerjinin atomik hacimle değișimi belirlendi. Şekil 3 te bu dört farklı yapı için E-V grafiği verilmiştir. Termodinamik açıdan minimum enerjili durum o sistemin kararlı yapısına karşılık gelmektedir.

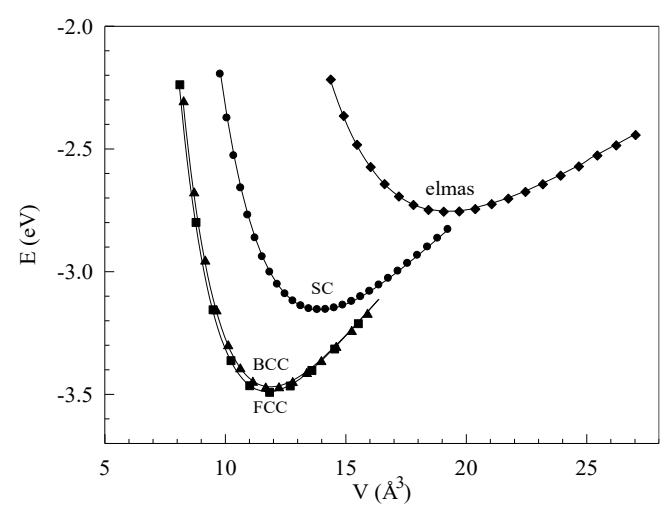

Şekil 3. $\mathrm{Cu}$ elementinin 4 farklı yapısı için kohesif enerjinin atomik hacminle değişimi.

Şekil 3 ten görüldüğü gibi 4 farklı yapı için potansiyel enerji fonksiyonu en düşük enerjili durumu $\mathrm{Cu}$ atomlarının fcc örgü noktaları yerleștirilmesi sonucu, en yüksek enerjili durumu ise atomların elmas örgü noktalarına yerleştirilmesi sonucu üretmiştir. $\mathrm{Cu}$ 
DEU FMD 21(61), 149-154, 2019

elementinin birim hücre yapısı literatürde fcc olarak verilmektedir [22].

SC potansiyel fonksiyonunun kararlı fcc yapısı için ürettiği kohesif enerji, kuvvet değerleri ve kübik kristaller için genelleștirilmiş durum denklemi olarak bilinen ve kristal örgü parametresine bağlı kristal enerjisini veren Rose enerjisinin [23] hacme bağlı değişimleri Şekil 4 te verilmiştir.

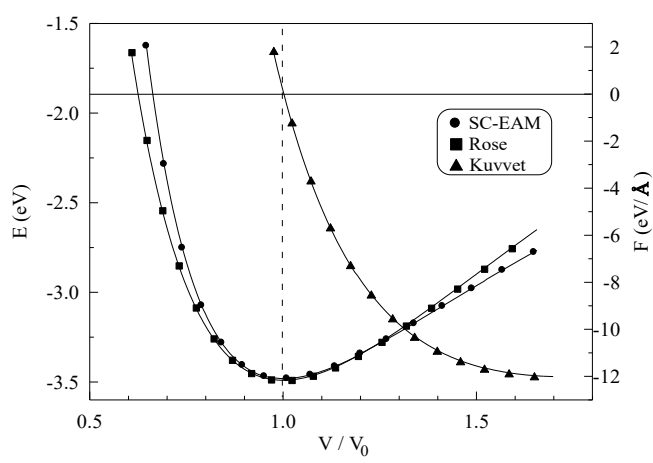

Şekil 4. Sutton-Chen, Rose enerjisi ve kuvvetin hacme bağlı değişimi.

SC potansiyel enerjisinin minimum değeri $-3,48$ $\mathrm{eV}$, Rose enerjisinin minimum enerji değeri $-3,49$ $\mathrm{eV}$ olarak belirlenmiştir. Elde edilen bu değerler literatürde $\mathrm{Cu}$ elementi için deneysel kohesif enerji değeri olan $-3,49 \mathrm{eV}$ ile uyum içindedir [24]. Ayrıca șekilden enerjinin minimum noktasında atomlar üzerine etki eden net kuvvet değerinin sıfırdan geçtiği de görülmektedir.

Şekil 5 te SC potansiyel fonksiyonunu oluşturan gömme enerjisi, ikili etkileme enerjisi, yük yoğunluğu bileşenlerinin hacim, atomlar arası uzaklık ve yük yoğunluğu değerleriyle değişimleri görülmektedir.
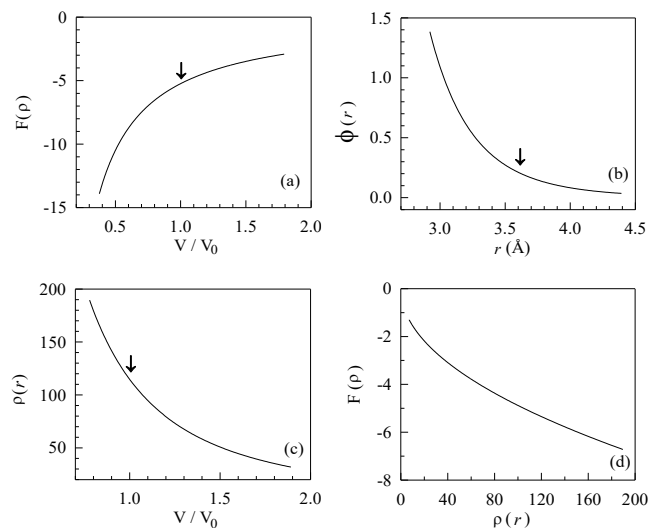

Şekil 5. SC potansiyel fonksiyonu bileșenlerinden (a) gömme enerjisinin hacimle (b) ikili etkileşme enerjisinin atomlar arası uzaklıkla, (c) yük yoğunluğunun hacim ile, (d) gömme enerjisinin yük yoğunluğu ile değişimi. $\downarrow$ işareti sistemin denge noktasını göstermektedir.

Şekil 5(a-b) SC potansiyel fonksiyonunun itici ve çekici etkileşme bileşenlerini göstermektedir. Şekil 5c de yük yoğunluğunun hacim ile değişimi görülmektedir. Hacmin artışı bir atomun bulunduğu bölgede diğer atomlardan kaynaklanan yük yoğunluğunun azaldığını göstermektedir. Şekil $5 \mathrm{~d}$ de ise yük yoğunluğundaki artışın gömme enerjisinde de bir artış meydana getirdiği görülmektedir. Başka bir ifadeyle yük yoğunluğunun artması bir atomu o noktaya gömmek için daha çok enerjiye ihtiyaç olduğunu söylemektedir.

Şekil 6 da model $\mathrm{Cu}$ sistemine uygulanan Bain zorlanmasına karșı kohesif enerji değișimi verilmiştir. Eğrinin $\varepsilon=0$ da ve $\varepsilon=0,148$ değerinde iki minimuma sahip olduğu görülmektedir. $\varepsilon=0$ değerinde sistem kararlı fcc yapısına sahiptir. Bu noktada sistemin sahip olduğu enerji değeri $\mathrm{E}^{\mathrm{f}}=$ $-3,489 \mathrm{eV}$ tur. İkinci minimum sistemin yarı kararlı durumuna karşılık gelmektedir ve burada sistem $\mathrm{E}^{\mathrm{b}}=-3,463 \mathrm{eV}$ enerji değeriyle bcc yapıya sahiptir. İki örgü yapısı arasındaki enerji farkı 0,026 eV değerindedir. Bu enerji engelinin aşılması durumunda fcc yapıda kararlı olan örgü bcc yapıya geçiş yapabilecektir. bcc yapı için zorlanmanın ideal değeri $\varepsilon=0,1225$ tir. Hesaplamalardan elde edilen 0,148 değeri ideal durumdan küçük bir sapma olduğunu göstermektedir. $\mathrm{Bu}$ durum $\mathrm{Cu}$ model sisteminin bcc birim hücreli yapıdan ziyade bct birim hücreli yapıya doğru kayma eğiliminde olduğunu ifade etmektedir.

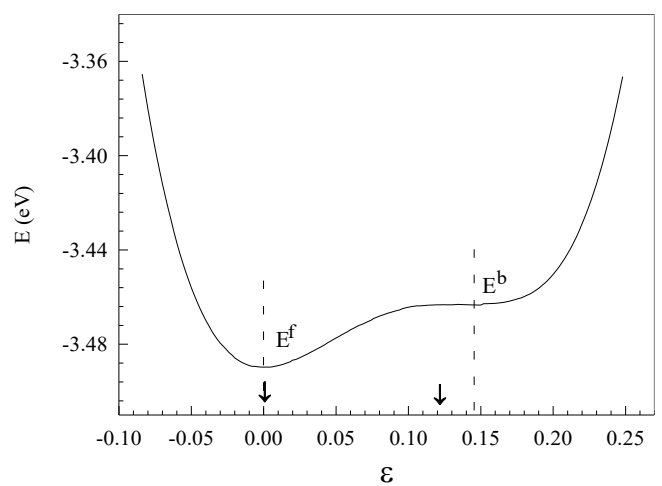

Şekil 6. Bain zorlanmasına karşı kohesif enerjideki değişim. 
DEU FMD 21(61), 149-154, 2019

Şekil 7 de $\mathrm{Cu}$ atomlarının küp șeklindeki hesaplama hücresi içine yerleștirildiği model sistemin [010] doğrultusu boyunca uygulanan kesme zoruna karşı enerjideki değişimi görülmektedir. Uygulanan kesme zoruna karşı ikinci bir yarı kararlı enerji noktası elde edilmemiştir. Sistemin hacmi sabit tutulmuş sadece atomik düzlemlerin birbiri üzerinde kaymasına izin verilmiștir.

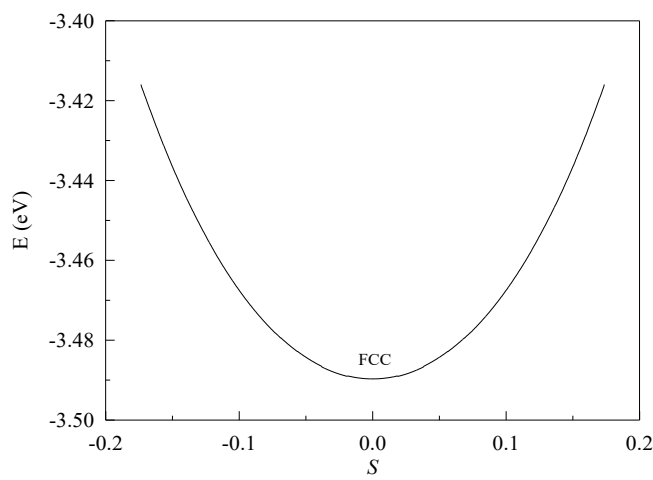

Şekil 7. Kesme zoru ile kohesif enerjideki değişim.

Şekil 8 de model $\mathrm{Cu}$ sistemine $S=0$ değerinden başlayarak $1,54 \times 10^{-2}$ aralıklarla $S=0,17$ değerine kadar 11 farklı kesme zoru altında Bain zorlanması uygulanması sonucu elde edilen enerji değișimi görülmektedir. $\varepsilon=0$ değerinde bütün zorlanma değerlerinde $\mathrm{Cu}$ elementinin fcc yapıda olduğu görülmektedir. Bununla birlikte kesme zorunun artmasıyla fcc yapının çok az bir değerde de olsa sıfırdan uzaklaştığ görülmektedir. Ayrıca $\mathrm{Cu}$ elementine uygulanan kesme zorunun artmasıyla bcc yapının ideal değeri olan $\varepsilon=0,1225$ den uzaklaşıldığı ve $\varepsilon=0,202$ değerinde bct birim hücreli bir yapıya doğru dönüşüm gösterebileceği görülmektedir. Bununla birlikte, Şekil 8 den kesme zorunun artmasıyla fcc ve bcc yapılar arasındaki enerji farkının da arttığı görülmektedir. Bu fark enerji miktarının artması, yüksek kesme değerlerinde sistemin bct birim hücreli yapıda kararlı olma isteği içinde bulunduğunu ve ters dönüşümün meydana gelebilmesi için daha yüksek enerjiye ihtiyaç duyulduğunu ifade etmektedir.

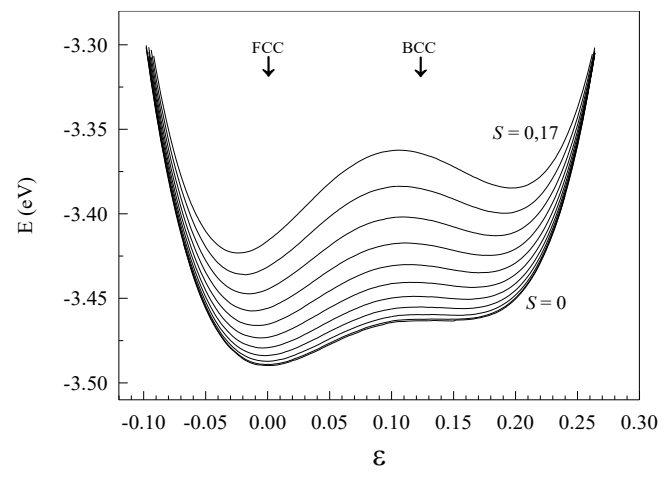

Şekil 8. Farklı kesme zoru șiddetlerine göre örgü enerjisinin Bain zorlanması ile değișimi.

\section{Tartışma ve Sonuç}

Sonuç olarak bu çalışmada kullanılan çok cisim etkileșme terimlerini içeren Gömülmüș Atom Metodunun Sutton-Chen yapisının katı-katı faz dönüşümlerinin temel teorilerinden olan Bain zorlanmasını gerçekleștirdiği görülmektedir. Model sisteme uygulanan kesme zorunun sistemin enerjisinde bir değișim meydana getirmediği ancak bain zorlanması altında uygulanan kesme zorunun model sistemi kararlı bir bct yapıya doğru sürüklediği belirlenmiștir. Ayrica Sutton-Chen potansiyel fonksiyonunun, anharmonik etkileșmelerin baskın olduğu faz dönüşümlerinin moleküler dinamik benzetim metoduyla incelenmesinde güvenle kullanılabileceği de söylenebilir.

\section{Kaynakça}

[1] Donato, M.G., Ballone, P. and Giaquinta P.V. 2000. Bain transformation in CuxPd1-x (x 0.5) alloys: An embedded atom study, Phys. Rev. B, 61(1), 24-27. DOI: $10.1103 /$ PhysRevB.61.24

[2] Christian, J.W. 1994. Crystallographic theories, interface structure, and transformation mechanism, Metall. and Mater. Trans. A, 25A, 18211836.DOI:https://doi.org/10.1007/BF02649031

[3] Kazanc, S., Ciftci, Y.O., Colakoglu, K., Ozgen, S. 2006. Temperature and pressure dependence of the some elastic and lattice dynamical properties of copper: a molecular dynamics study, Physica B, 381, 96-102. DOI: https://doi.org/10.1016/j.physb.2005.12.259

[4] Dahal, S., Kafle, G., Kaphle, G. C. and Adhikari, N. P. 2014. Study of Electronic and Magnetic Properties of $\mathrm{CuPd}, \mathrm{CuPt}, \mathrm{Cu}_{3} \mathrm{Pd}$ and $\mathrm{Cu}_{3} \mathrm{Pt}$ : Tight Binding Linear Muffin-Tin Orbitals Approach Journal of Institute of Science and Technology, 19(1), 137144.DOI:http://dx.doi.org/10.3126/jist.v19i1.138 39

[5] Karavaev, A.V., Dremov, V.V., Ionov, G.V. 2017. Atomistic simulations of dislocation dynamics in d- 
DEU FMD 21(61), 149-154, 2019

Pu-Ga alloys, Journal of Nuclear Materials, 496, 8596. DOI: 10.1016/j.jnucmat.2017.09.005

[6] Mittal, R., Gupta, M.K., Chaplot, S.L. 2018. Phonons and anomalous thermal expansion behaviour in crystalline solids, Progress in Materials Science, 92 360-445. DOI: arXiv:1711.07267

[7] Erkoç, Ş. 1997. Emprical many-body potential energy functions used in computer simulationo condensed matter properties, Physics Reports, 278 79-105. DOI: https://doi.org/10.1016/S0370$\underline{1573(96) 00031-2}$

[8] Silayi, S., Papaconstantopoulos, D.A., Mehl M.J. 2018. A tight-binding molecular dynamics study of the noble metals $\mathrm{Cu}, \mathrm{Ag}$ and $\mathrm{Au}$, Computational Materials Science, 146, 278-286.

[9] Kazanc, S. 2004. Bakır Bazlı Alașımlarda Termoelastik Dönüşümlerin Moleküler Dinamik Benzetimi, Fırat Üniversitesi, doktora Tezi, Elazı̆̆

[10] Kazanc, S., Özgen, S. 2004. The Changes of barrier energy in fcc-bcc phase transformation by shear stresses, G.U. Journal of Science, 17(2), 35-42.

[11] Daw, M.S., Hatcher, R.D. 1985. Application of the embedded atom method to phonons in transition metals, Solid State Comm, 56, 697-699. DOI https://doi.org/10.1016/0038-1098(85)90781-1

[12] Voter, A.F., Chen, S.P. 1987. Accurate Interatomic Potentials for $\mathrm{Ni}, \mathrm{Al}$, and $\mathrm{Ni}_{3} \mathrm{Al}$, Mat. Res. Soc. Symp. Proc., 82, 175. DOI: https://doi.org/10.1557/PROC$\underline{82-175}$

[13] Finnis, M.W and Sinclair JE 1984 A simple empirical N-body potential for transition metals Philosophical Magazine, 50, 45-55. DOI https://doi.org/10.1080/01418618408244210

[14] Ferrando, R., Tréglia, G. 1995. Tight binding molecular dynamics study of diffusion on $\mathrm{Au}$ and Ag(111), Surface Science, 331-333, 920-924. DOI: https://doi.org/10.1016/0039-6028(95)00276-6

[15] Sutton, A.P., Chen, J. 1990. Long-range FinnisSinclair potentials, J. Philosophical Magazine Letter 61,139-146.DOI: https://doi.org/10.1080/09500839008206493

[16] Khoei,A.R., Abdolhosseini,M.J., Kazemi, M.T., Aghaei A. 2009. An investigation on the validity of CauchyBorn hypothesis using Sutton-Chen many body potential Computational Materials Science, 44(3) 999-1006. DOI:10.1016/j.commatsci.2008.07.022

[17] Xia, W., Chen, S., Sun, Y., Chen, Y. 2012. Geometrical structures of gold clusters on Gupta and SuttonChen potentials, Computational and Theoretica Chemistry, 1002, 43-48. DOI:10.1021/ja102145g

[18] Kazanc, S. 2006. Molecular dynamics study of pressure effect on glass formation and the crystallization in liquid $\mathrm{CuNi}$ alloy, Computational Materials Science, 38(2), 405-409. DOI: https://doi.org/10.1016/j.commatsci.2006.03.008
[19] Nishiyama, Z. 1978. Martensitic transformation Academic press, New York.

[20] Suziki, T., Shimono, M., Kajiwara, S. 2001. On the mechanism for martensitic transformation from fcc to bcc, Mater. Sci. and Engin. A, 312, 104-108. DOI: https://doi.org/10.1016/S0921-5093(00)01862-1

[21] Daw, M.S. and Baskes, M.I. 1983. Semiemprical, Quantum mechanical calculation of hydrogen embrittlement in metals, Physical Rewiev Letter, 50(17),1285-1288.DOI: doi.org/10.1103/PhysRevLett.50.1285

[22] Cagin, T., Dereli, G., Uludogan, M. and Tomak, M. 1999. Thermal and mechanical properties of some fcc transition metals, Phys. Rev. B, 59(4), 34683472. DOI: doi.org/10.1103/PhysRevB.59.3468

[23] Rose, J.H., Smith, J.R., Guinea, F. and Ferrante, J. 1984. Universal Features of the equation of state of metals, Physical Rewiev B, 29(6), 2963-2969. DOI: https://doi.org/10.1103/PhysRevB.29.2963

[24] Kittel, C. 1986. Introduction to solid state physics, John Wiley\&Sons, Inc., New York. 